\title{
Abordagem psicossocial do diagnóstico inicial na oncopediatria
}

\author{
Psychosocial approach to initial diagnosis in oncopediatry \\ Enfoque psicossocial del diagnóstico inicial em oncopediatría
}

Ana Clara Mendes Freitas ${ }^{1 *}$, Arlan Lemes Vilela1, Gabriela Fischer Lemes Ferraz ${ }^{1}$, Gabrielle Marcon ${ }^{1}$, José Luis Quelho Filho ${ }^{1}$, Luísa Conte Gonçalves ${ }^{1}$, Maria Eduarda Pereira de Souza ${ }^{1}$, Mylla Silva Braga ${ }^{1}$, Socorro Andrade de Lima Pompilio'.

\begin{abstract}
RESUMO
Objetivo: Analisar o impacto psicossocial do paciente pediátrico no pós-diagnóstico oncológico, a fim de identificar as estratégias de enfrentamento e a repercussão emocional após o diagnóstico de câncer. Métodos: Estudo descritivo qualitativo realizado com crianças de 8 a 12 anos de idade, que receberam diagnóstico de câncer nos últimos 90 dias da pesquisa. Foram coletados os dados por meio da aplicação de questionário semiestruturado após o consentimento e assentimento dos participantes. Resultados: A ausência de comunicação efetiva entre profissionais de saúde e pacientes mostrou dificultar a identificação de emoções, prevalecendo sentimentos complexos. Mesmo diante da singularidade de cada paciente, as mudanças de vida geraram tristeza e desprezo. Além de apresentaram sentimento de impotência e comportamentos de defesa ao falar do processo de adoecimento. Conclusão: A boa relação médico-paciente-família é indispensável frente ao diagnóstico e tratamento do câncer infantil; destacando, a necessidade de adequação da comunicação, trazendo ludicidade para compreensão cognitiva infantil de sua situação a fim de promover maior aceitação e melhor prognóstico.
\end{abstract}

Palavras-Chave: Oncologia, Pediatria; Adaptação psicológica, Educação médica.

\section{ABSTRACT}

Objective: Analyze the psychosocial impact of the pediatric patient in the post-cancer diagnosis, in order to identify the coping strategies and the emotional repercussion after the cancer diagnosis. Methods: Qualitative descriptive study carried on children aged 8 to 12 years, who were diagnosed with cancer in the last 90 days of the research. Data were collected through the application of a semi-structured questionnaire after the consent and consent of the participants. Results: The absence of effective communication between health professionals and patients proved to make it difficult to identify emotions, with complex feelings prevailing. Even in the face of the uniqueness of each patient, life changes generated sadness and contempt. In addition to showing a feeling of helplessness and defensive behaviors when talking about the illness process. Conclusion: A good doctor-patient-family relationship is indispensable when diagnosing and treating childhood cancer; highlighting the need for adequate communication, bringing playfulness to children's cognitive understanding of their situation in order to promote greater acceptance, effectiveness and therapeutic humanization.

Keywords: Medical oncology, Pediatrics, Adaptation psychological, Education medical.

\section{RESUMEN}

Objetivo: Analizar el impacto psicosocial del paciente pediátrico en el diagnóstico post-cáncer, con el fin de identificar las estrategias para afrontarlo y la repercusión emocional tras el diagnóstico de cáncer. Métodos: Estudio descriptivo cualitativo realizado en niños de 8 a 12 años, que fueron diagnosticados de cáncer en los últimos 90 días de la investigación. Los datos fueron recolectados mediante la aplicación de un cuestionario semiestructurado previo consentimiento de los participantes. Resultados: La ausencia de una comunicación eficaz entre los profesionales sanitarios y los pacientes dificulta la identificación de las emociones, predominando los sentimientos complejos. Incluso ante la singularidad de cada paciente, los cambios de vida generaron tristeza y rechazo. Además de mostrar un sentimiento de impotencia y conductas defensivas cuando se habla del proceso de la enfermedad.

${ }^{1}$ Universidade Anhanguera (UNIDERP), Campo Grande - MS. *E-mail: anaclarafreitas2417@gmail.com. 
Conclusión: Una buena relación médico-paciente-familia es indispensable para diagnosticar y tratar el cáncer infantil; destacando la necesidad de una comunicación adecuada, incorporando actividades lúdicas a la comprensión cognitiva de los niños de su situación, con el fin de promover una mayor aceptación, efectividad y humanización terapéutica.

Palabras clave: Oncología médica, Pediatría, Adaptación psicológica, Educación médica.

\section{INTRODUÇÃO}

O diagnóstico oncológico é acompanhado por uma série de mudanças, não apenas físicas, mas também emocionais e sociais. Segundo Brum MV e Aquino GB (2014), mesmo diante da ampliação dos conhecimentos atuais sobre a doença, ainda é responsável por abalar drasticamente os envolvidos, gerando sentimentos de medo e angústia. As consequências podem ser ainda maiores quando o diagnóstico incide em um indivíduo durante a infância, fase caracterizada pela grande vulnerabilidade. Devido a essa vulnerabilidade e complexidade do diagnóstico, todo o processo de tratamento deve ser realizado por equipe multidisciplinar, assegurando assistência ao paciente e seus familiares sob inúmeras perspectivas físicas e psicológicas (COSTA TF e CEOLIM MF, 2010).

De acordo com Françoso LPC (2016), cada criança vive as situações relacionadas à sua doença e ao tratamento de forma única. Portanto, é importante adentrar a sua história de adoecimento a fim de possibilitar o conhecimento do processo, buscando delinear o sentido que a mesma está atribuindo às experiências que vivencia.

A criança, em seu processo de adoecimento, afeta a estrutura familiar, devido ao momento de incertezas e vulnerabilidade, gerando estresse e angústia por todos. $O$ apoio psicoemocional torna-se fundamental para minimizar tais fatores estressantes. (VALVERDE DLD e CARNEIRO MPSR, 2011). Vieira CS, et al. (2010) afirmam que diante da existência de relações sociais é possível haver apoio social. Através deste, pacientes recebem apoio emocional, afetivo, material, informação para enfrentarem situações adversas, a fim de gerar maior qualidade de vida com a melhoria da saúde.

Estressores psicológicos como medo, pressão, tensões, situações de ameaça e inseguranças geram sinais que vão para o Sistema Límbico que ativa o Sistema Nervoso Autônomo Simpático (SNAS) e o Eixo hipotálamo-hipófise-adrenal (HHA). Estes liberam catecolaminas e glicocorticóide, principalmente o cortisol; que reduz a produção de lipocortina, inibindo a interleucina-2, que diminui a síntese de linfócitos $\mathrm{T}$, macrófagos, serotonina e células natural-killers. Dessa forma, desencadeia uma supressão global do sistema imunológico (FONSECA NC, et al., 2014).

No diagnóstico recente, ocorrem os maiores indícios de medo, ansiedade e estresse; é um momento de busca por adaptação por parte da criança, que vivencia uma situação impactante em sua vida. Devido a essa instabilidade emocional, pode haver o desequilíbrio entre as estratégias de enfrentamento positivas e negativas, gerando risco psicossocial. Sendo, portanto, um momento imprescindível para a intervenção psicológica precoce a fim de gerar apoio (HILDEBRAND et al., 2011; CAPRINIL FR e MOTTALL AB, 2017).

Os períodos da infância e adolescência possuem singularidades, desta forma o vínculo e a comunicação como suporte e acolhimento geram melhor manejo clínico e psicoemocional do paciente em sua individualidade. O rapport (conceito usado na psicologia para criar uma ligação de sintonia e empatia com outra pessoa) possibilita a visão ampliada da pessoa enferma e que aspectos além do biológico precisam ser levados em consideração sob o risco de causar alguma forma de dano ao paciente (SEI MB e ZUANAZZI AC, 2016). A habilidade de comunicação faz parte dos recursos terapêuticos que o profissional médico precisa desenvolver, pois quando não está plenamente habilitado, sua ação pode ter efeitos iatrogênicos (PIMENTEL CMA, et al., 2020)

Assim, o objetivo deste estudo foi analisar o impacto biopsicossocial dos pacientes pediátricos oncológicos, a fim de identificar as estratégias de enfrentamento no processo da infância e a repercussão emocional após o diagnóstico de câncer infantil. 


\section{MÉTODOS}

A pesquisa foi realizada com crianças entre 8 a 12 anos de idade que receberam diagnóstico de câncer nos últimos 90 dias até o mês de dezembro de 2019. As idades selecionadas são justificadas pela necessidade da compreensão da criança acerca dos instrumentos da pesquisa, enquanto o período pós diagnóstico limitado pode restringir as possibilidades de enfrentamento. As crianças com diagnóstico recidivo e em tratamento intensivo não participam dos critérios para o estudo, uma vez que já passaram da fase inicial do diagnóstico. Desta forma, 3 crianças se encaixaram nos critérios de inclusão e realizaram o estudo.

Para a avaliação do pensar, agir e sentir das crianças hospitalizadas, foi utilizado um questionário de entrevista semiestruturada, contendo onze (11) perguntas subjetivas elaboradas pelos pesquisadores. As perguntas buscaram avaliar por meio do relato da criança, aspectos a respeito de como, quando e onde 0 diagnóstico foi apresentado a ela; como ela se sentiu em relação ao mesmo; o que a doença implica na sua vida atual e como o paciente se sente hoje. Em três (3) perguntas, foi fornecido à criança uma tabela de "emojis" para auxiliar a classificar o seu sentimento, que representam oito (8) emoções básicas universais: neutro, alegria, raiva, tristeza, desprezo, surpresa, aversão e medo.

Antes da coleta de dados, a família foi contactada para o esclarecimento sobre os princípios de autonomia e privacidade, bem como a confidencialidade dos procedimentos, a priorização do bem-estar da criança e o caráter voluntário de sua participação. Após obter o assentimento da criança (Termo de Assentimento) e o consentimento do responsável (Termo de Consentimento Livre e Esclarecido), foram realizadas as técnicas de entrevista, a mesma foi gravada e seguiu um roteiro sistemático, transcritas após a coleta.

O depoimento foi submetido a técnicas de análise das comunicações, que constituem a análise de conteúdo, de acordo com Bardin L (2011), que propõe fases de condução, que iniciam com a organização da análise, a codificação das falas, sua categorização e o tratamento dos resultados, inferência e a interpretação dos resultados. Foi realizado um instrumento de coleta de dados que corroborasse trazer elementos (sintagmas) do corpus que pudessem codificá-los para passar para a próxima etapa para a categorização.

À luz de uma releitura da metodologia de análise de conteúdo proposta por Bardin L (2011) e em consonância com os objetivos da pesquisa, elegeu-se as seguintes categorias de análise: aspectos relacionados ao conhecimento da sua doença, aspectos psicoemocionais, aspectos restritivos da doença e aspectos de enfrentamento. Para cada categoria, foram elencadas subcategorias como resultado da imersão do pesquisador nas respostas dos sujeitos (identificados como E1, E2 e E3) às perguntas abertas do roteiro de entrevista (identificados com questões (QS)). Quanto às unidades de contexto, optou-se por recortes temáticos, materializados em frases nominais. Diante as unidades de contexto, foram selecionados recortes das falas dos sujeitos em respostas às questões.

A primeira categoria, os "aspectos relacionados ao conhecimento da sua doença", buscou emergir o grau da compreensão do diagnóstico que a doença tem para o entrevistado, partindo de como ele recebeu a notícia, por quem ele recebeu e onde estava no momento.

A segunda categoria os "aspectos psicoemocionais" envolvidos, classificou como subcategoria emoção e sentimentos que envolvem os entrevistados, a patologia, os percalços advindos da doença e a entrevista em si.

A terceira categoria os "aspectos restritivos da doença", investigou as restrições físicas e sociais, cuja intenção foi conhecer o impacto da patologia no cotidiano dos entrevistados, as limitações que advém com o tratamento.

A quarta categoria os "aspectos de enfrentamento", relaciona-se a subcategoria a insegurança e esperança, por mais que esses subjetivos podem ser classificados como sentimentos, buscou analisar na fala dos entrevistados características que trouxessem à tona os esforços cognitivos e/ou comportamentais dos indivíduos, que podem causar um maior estresse ou recursos positivos no processo de tratamento.

As falas dos entrevistados foram descritas conforme foram apresentadas foneticamente, portanto, muitas falas são monossilábicas, apresentam gestos e acenos para as perguntas, a comunicação não verbal foi captada pelo entrevistador e descrita em complementação à resposta verbal redigida do entrevistado (sinalizada em negrito e parênteses). 
Foi utilizada entrevista semiestruturada em diálogo, inserindo situações do cotidiano ou mostrando interesse pelos objetos que o entrevistado manuseava com o cuidado de os tranquilizar e também seus acompanhantes no sentido de favorecer uma maior aproximação afetiva e possibilitar uma melhor confiabilidade das respostas à pesquisa. Os dados foram sistematizados em quadros, apresentados na sequência, que foram submetidos à análise e interpretação.

\section{RESULTADOS}

No primeiro momento da entrevista, buscou-se traçar o conhecimento dos entrevistados sobre a doença (Quadro 1). Quando questionado sobre, ao entrevistado 1, relatou somente os aspectos físicos, sem muita compreensão sobre o assunto. $O$ mesmo aconteceu com o entrevistado 3 , que mesmo tendo a interferência da mãe relatando que o diagnóstico foi dito por ela, o entrevistado teve ciência pela observação de uma mancha.

$\mathrm{O}$ que demonstra que foi pouco elucidativo para os entrevistados 1 e 3 o conhecimento sobre seus diagnósticos, sendo essas informações dadas pelas suas mães, ainda com escassa clareza. $O$ dado físico dor e mancha - aparece no discurso como sinalizador da doença para E1 e E3.

O entrevistado 2 não relatou sobre o grau de compreensão da doença. Quando respondia algo, adotava respostas evasivas e negativas, ou falava com sua mãe na língua nativa (outra nacionalidade). A mãe serviu de intérprete na obtenção dos dados.

Quadro 1 - Aspectos relacionados à doença.

\section{QUESTIONÁRIOS (QS)}

Quando você soube que estava doente, quem te contou? (Vamos lembrar um pouco desse dia.../ Como falaram isso para você?).

Você lembra desse dia? Você lembra onde estavam? (Onde você estava? Quem estava com você?).

\section{CATEGORIAS}

Aspectos relacionados à doença

\section{SUBCATEGORIAS}

Compreensão da doença/diagnóstico

\section{UNIDADES DE CONTEXTO (RECORTES DAS FALAS)}

E1 (12 anos) "É... não sei explicar isso"

"É que eu perguntei mesmo o que eu tinha que o médico só estava falando e ela (a mãe) explicou que eu tinha uma massa, e isso..."

"É que eu senti muita dor. Tipo, quando atacava."
E2 (10 anos) "Não"

(Não quis responder).

(Mãe respondeu) "Foi mês passado. Foi mês passado que eu contei pra ela. Ela nem sabia o que era leucemia mesmo. Pra ela pequena não tem nem ideia o que é câncer. Então eu só conto pra ela que é leucemia. Que é uma doença grave."
E3 (08 anos) "Ninguém me contou"

"A mãe contou pra você! Lembra que a gente foi em Ponta-Porã, fez a coleta de sangue e daí veio para cá...?" (a mãe interviu na entrevista relatando)

"Eu sei, mas não foi. Foi quando começou a sair uma mancha..."

\section{Fonte: Freitas ACM, et al., 2020.}

No segundo momento foi para a análise da outra categoria elencada, os "aspectos psicossociais envolvidos", utilizando o instrumento balizador, os emojis apontados pelos entrevistados que distinguiram os sentimentos e emoções envolvidas (Quadro 2). 
As impressões dos entrevistadores foram registadas quanto à postura corporal e a fisionomia dos entrevistados, descrevendo-as ao final de cada interlocução a fim de contribuir com os dados coletados durante a pesquisa.

O E1 iniciou a entrevista de maneira acuada e com fisionomia entristecida e, ao decorrer da entrevista, ajustou-se numa postura mais ereta e ficou mais falante. Ao final, quando saiu da sala, fez algumas piadas e expressou de forma não verbal uma expressão de alegria.

O E2 apresentou-se alegre desde o início, porém não gostava de falar em português e se referia a mãe antes da entrevistadora. Deu muitas risadas durante a entrevista e recebeu as perguntas com aparente leveza, bem como sua mãe. Quando falado sobre a doença, sua postura se encolheu, mas ao mudar de assunto, normalizou-se.

O E3, desde o início, estava com a fisionomia entristecida, respondia as respostas de maneira agressiva e sem vontade. Não estabeleceu contato visual durante toda a entrevista, sempre olhando para baixo e a postura fechada, acuada.

Quadro 2 - Aspectos psicoemocionais envolvidos.

\section{QUESTIONÁRIOS (QS)}

Você percebeu alguma mudança na sua casa? (Depois que sua família ficou sabendo que você estava doente, mudou alguma coisa?)

Caso houve alguma mudança, como você se sente em relação a isso? O que você acha? (Tabela de

Emojis para auxílio)

\section{CATEGORIAS}

Aspectos psicoemocionais

\section{SUBCATEGORIAS}

Sentimentos e emoções

\section{UNIDADES DE CONTEXTO (RECORTES DAS FALAS)}

E1 (12 anos) "Tudo isso aí". "É esse também. Porque quando ele falou que ia me transferir. Que deu certo e que ia me transferir eu fiquei feliz" "Porque ele me chamou de moleque"

"Também, quando eu descobri que eu tinha tumor"
E2 (10 anos) Não (Risada) É porque cinco meses depois já. Ela já sabia que era uma doença grave.

Ela já foi aceitando aos poucos. Então foi contado no mês passado (mãe que interviu).

E2 (10 anos) "Sim" "Tudo tem que cozinhar. Tudo tem que ser limpinho, passar álcool. Isso ela não gosta" (mãe que interviu).
E3 (08 anos) "É que toda hora de dia ficam me chamando quando eu estou no hospital... Ali fora, assim. Não quero ir lá pra fora".

\section{EMOJIS}

Apontou todos os emojis

Feliz

Raiva

Tristeza

A entrevistada não apontou

Raiva

Raiva

Fonte: Freitas ACM, et al., 2020.

O Quadro 3 apresenta os aspectos restritivos sociais e físicos ocasionados pela doença, assim foi questionado a cada entrevistado o que deixou de fazer após o diagnóstico, e qual o sentimento que isso lhe causava. 
Atividades corriqueiras como apenas "sair de casa" (E1) ou o simples ato de alimentar- se, como expôs o E2 "a comida" e apontou o "emoji" da raiva; são dificultadas, pois, após o diagnóstico e durante o tratamento, a criança fica debilitada. $O$ adoecer apresenta muitos impeditivos de ações e brincadeiras cotidianas na vida das crianças. Os entrevistados apontaram atividades como "andar de cavalo", brincar de bola (E1), "trepar em árvore" (E3), "montar lego" (E2). Isso mostra que eram brincadeiras que lhe davam prazer e remetiam a vivência da infância, o que gera consequentes sentimentos de desprezo e tristeza, apontadas pelos "emojis".

Outro dado observado foi com relação à escola, em alguns momentos a criança pôde apresentar que não se interessa pela escola, como comentado pelo E1; "Não sei. Porque depois que eu passei por isso eu parei de ir na escola. Mas eu não gosto porque depois do que aconteceu eu fiquei, digamos, frágil. Eu não sei responder as coisas direito"; ou pelo E3 que não quis responder, ficando em silêncio.

Quadro 3 - Aspectos restritivos da doença.

\section{QUESTIONÁRIOS (QS)}

A partir desse dia, você teve que deixar de fazer algo que gosta? E o que você acha disso?

Como é pra você deixar de fazer alguma coisa que gosta?

E você vai à escola? Mudou alguma coisa pra você? O que você acha da sua escola?

O que você mais gosta de fazer? Você ainda faz isso? Se não, por quê?

\section{CATEGORIAS}

Aspectos restritivos da doença

\section{SUBCATEGORIAS}

Físicos e sociais

\section{UNIDADES DE CONTEXTO (RECORTES DAS FALAS)}

\begin{tabular}{|c|c|c|}
\hline \multicolumn{3}{|c|}{ UNIDADES DE CONTEXTO (RECORTES DAS FALAS) } \\
\hline $\begin{array}{l}\text { E1 (12 anos) "Sair da minha } \\
\text { casa e de andar de cavalo". } \\
\text { "Nenhum lugar, porque agora } \\
\text { eu não posso" "Brincar de } \\
\text { bola". } \\
\text { "Não sei. Porque depois que } \\
\text { eu passei por isso eu parei de } \\
\text { ir na escola. Mas eu não gosto } \\
\text { porque depois do que } \\
\text { aconteceu eu fiquei, digamos, } \\
\text { frágil. Eu não sei responder as } \\
\text { coisas direito". }\end{array}$ & $\begin{array}{c}\text { E2 (10 anos) Sim! Comida! Mãe: Sim! } \\
\text { Tudo tem que cozinhar. Tudo tem que } \\
\text { ser limpinho, passar álcool. Isso ela não } \\
\text { gosta } \\
\text { "Ela acha muito incomodado. Antes ela } \\
\text { comia à vontade, podia pegar qualquer } \\
\text { comida e comer. Agora não, tem que } \\
\text { lavar. Tem que lavar. Lavar bem. Assim } \\
\text { não. Assim é chato" (Mãe) } \\
\text { "Ela é muito inteligente. Então quando } \\
\text { ela teve a doença ela teve que parar de } \\
\text { estudar e ela ficou bem triste que teve } \\
\text { que parar a escola" (Mãe) } \\
\text { "Monta né" "Montar Lego" (Mãe) } \\
\text { Não. (Olha mãos). (Mãe aponta que a } \\
\text { criança monta Lego). } \\
\text { "Porque unha quebra" (Mãe) }\end{array}$ & $\begin{array}{c}\text { E3 (08 anos) "Brincava, mas } \\
\text { agora não estou mais } \\
\text { brincando". } \\
\text { "Trepar em árvore". }\end{array}$ \\
\hline \multicolumn{3}{|c|}{ EMOJIS } \\
\hline Desprezo & Raiva & Desprezo \\
\hline
\end{tabular}

Fonte: Freitas ACM, et al., 2020.

Já o Quadro 4 buscou traçar características de enfrentamento dos entrevistados com relação a doença. Nessa perspectiva, contou a história do Aladim e o gênio da Lâmpada, na qual, a história lhe permite fazer os três desejos. 
O E1 respondeu: "Pra ir pra casa e não precisar vir aqui de novo", "um laptop" e "ser veterinário". Ainda questionou ao entrevistado se pensava no futuro, ele disse que sim. A E2 não soube responder nenhuma das questões levantadas. E, E3 falou que não pediria nada e ficou em silêncio mesmo a mãe contando a história que "um dia estava olhando pro céu você falou se cair uma estrela faz um pedido pra mim?". E mesmo com o questionamento da entrevistadora falando o que ele queria ser quando crescer, o E3 falou: "não quero ser nada".

Quadro 4- Aspectos de enfrentamento.

QUESTIONÁRIOS (QS)

Faz de conta que você encontrou o gênio da lâmpada e ele te deu três pedidos, o que você pediria?

Como você se imagina no futuro? E o que você gostaria de realizar quando crescer?

\section{CATEGORIAS}

Aspectos de enfrentamento

\section{SUBCATEGORIAS}

Positividade e negação

\section{UNIDADES DE CONTEXTO (RECORTES DAS FALAS)}

\begin{tabular}{|c|c|c|}
\hline $\begin{array}{c}\text { E1 (12 anos) Pra ir pra casa e não } \\
\text { precisar vir aqui de novo. } \\
\begin{array}{c}\text { Eu vou ser veterinário Meu sonho é } \\
\text { ser youtuber }\end{array}\end{array}$ & $\begin{array}{c}\text { E2 (10 anos anos) Curada! } \\
\text { (mãe) }\end{array}$ & $\begin{array}{c}\text { Não. (Você pode me contar, R.?) } \\
\text { É que toda hora de dia ficam me } \\
\text { chamando quando eu estou no } \\
\text { hospital... Ali fora, assim. Não } \\
\text { quero ir lá pra fora. } \\
\text { Nada (Silencio) }\end{array}$ \\
& & Não ganha nada de bom. \\
\hline
\end{tabular}

Fonte: Freitas ACM, et al., 2020.

\section{DISCUSSÃO}

Diante do exposto, há escassez de informação frente ao diagnóstico oncológico. Conforme exposto por D'Alessandro D (2020), ambientes estressantes, como o setor oncológico, faz-se necessário adaptações na comunicação a fim de gerar compreensão e interação na relação paciente-equipe médica. Desta forma, com uma comunicação efetiva, há o estabelecimento de confiança e conexão nesse binômio, colaborando no envolvimento do processo, que auxiliará no processo terapêutico.

Como relatado por Trintenaro JC, et al. (2016), que a equipe de saúde possui papel de falar com o paciente sobre o seu diagnóstico, cuja comunicação é o entendimento entre as pessoas. Todavia, esse entendimento pode não ser alcançado, devido à influência de fatores, como nível de instrução, cognição, cultura e idade, que podem comprometer a qualidade da comunicação.

Cabe salientar que a concepção da doença da criança é diferente do adulto, pois ela não compreende o conceito da doença ou até mesmo da cura. A idade interfere diretamente na capacidade de compreender o que é um hospital e o que está fazendo nele, então quanto menos idade, menor a compreensão.

Desta forma, é necessário ter uma visão ampla da família, dos sentimentos e das dificuldades socioeconômicas e culturais, devolvendo respeito, afeto, cuidado com as palavras, adaptando-se às especificidades de cada família (SANTOS ALM e PACHECO APA, 2010). 
O diagnóstico de câncer traz sentimentos complexos e difusos, trazendo reações emocionais e comportamentais da criança, a convivência com a dor não só física, resultante do tratamento, mas a dor emocional que passa a surgir como resposta para inúmeras situações (SOUZA LPS, 2012). O profissional que trabalha com crianças deve visualizar o mundo e compreender suas necessidades sob o ponto de vista infantil, abrangendo também as fases de desenvolvimento.

A utilização dos "emojis", como instrumento balizador, serve para auxiliar a criança a "identificar" os seus sentimentos, uma vez que este tipo de signo se tornou algo naturalizado, principalmente na faixa etária dos entrevistados. (PAIVA VLMO, 2016). Além de, propiciar aos profissionais e familiares a identificação dessas emoções, a fim de tornar o tratamento mais efetivo. A identificação das emoções, sentimentos, faz parte da inteligência emocional do indivíduo, ou seja, a sua capacidade de identificar seus sentimentos e os dos outros, de se motivar e de gerir essas emoções internas e aplicá-las nos relacionamentos (GOLEMAN D, 2011). O saber sobre as emoções e sentimentos do paciente oncológico pediátrico, é que direciona as ações de conforto e enfrentamento.

Ao analisar as posturas dos entrevistados durante os questionamentos, as fontes de percepção colhidas na entrevista foram ampliadas. Essa ação insere também os autores da pesquisa como fonte de dados, oferecendo maior possibilidade de análise do estudo. A comunicação vai além de gerar e captar informações; através da comunicação não verbal, cuja engloba gestos, silêncio, expressão facial, postura corporal, organização dos objetos no espaço, proxêmica e tacêsica, permite uma visão global das pessoas que se comunicam (OTANI MAP, 2013). Essa constatação auxilia na reflexão e consequente corresponsabilização do profissional de saúde em suas interações com os pacientes, pois a perspectiva comunicacional pode tornar-se terapêutica ou a iatrogênica, a depender de como ela se estabelece.

Devido à complexidade da doença, e os tipos de tratamentos alteram o ritmo de vida da criança; a cirurgia, a quimioterapia e a radioterapia atuam sobre o corpo da criança, deixando-a debilitada com dificuldade de locomoção e equilíbrio, fazendo com que a criança perca o desejo e a pulsão para brincar. Este, além de ser uma demanda de cuidado com vistas a favorecer o desenvolvimento infantil, é também fonte de prazer, transformando-se, assim, em um tipo de cuidado que convida à vida e ajuda na manutenção da vida dessas crianças (SILVA LF e CABRAL IE, 2014). O brincar, principalmente para a criança em ambiente hospitalar, entra em seu "espaço potencial"; momento de experiência que o indivíduo pode exercer sua espontaneidade e viver a sua criatividade, a fim de lidar com a realidade. (COSTA PF, 2016).

Cabe ressaltar que, no ato da entrevista, os entrevistados utilizavam celular/tablet, assistindo vídeos ou jogando. Esse instrumento é um recurso atrativo, considerando que trazer a ludicidade, de outras formas, é fundamental para o seu desenvolvimento cognitivo; tais recursos lúdicos minimizam a hostilidade do ambiente hospitalar, além de possibilitarem a liberação dos sentimentos das crianças provenientes do momento, como raiva e dor. $\mathrm{E}$, assim, há a possibilidade do brincar ser um elemento auto curativo, terapêutico e sinal de saúde, visto que aderem melhor ao tratamento, além de proporcionar um ambiente mais acolhedor. (SILVA PLN, et al., 2016).

Um exemplo é o brinquedo terapêutico, ressaltado por Souza LPS, et al. (2012), material utilizado nas sessões de brinquedo que constituiu-se de bonecos representando a família e a equipe hospitalar, objetos de uso doméstico ou do cotidiano (telefone, pratos, talheres, panelinhas, tigelas, revólver, carrinhos, mamadeira e material para desenho e pintura) e de uso hospitalar (equipo de soro, seringa, torneirinha, algodão, luva, garrote, esparadrapo, dispositivo de curta permanência com agulha metálica, gelco, frasco de medicamentos, copos para medicação, estetoscópio e tesoura).

Desse modo, o brinquedo torna-se terapêutico se utilizado com criatividade, tanto os objetos cotidianos, como os instrumentos de uso hospitalar; por exemplo, bonecos que representem a família ou mesmo fazer fantoche com as luvas. O que realmente importa é recuperar a socialização da criança por meio da inclusão, propiciar continuidade à sua aprendizagem e manter a criança o vínculo com seu mundo exterior (SOUZA LPS, et al., 2012). Para minimizar as perdas cotidianas e de desenvolvimento das crianças, muitos hospitais dispõem de classes hospitalares que fazem acompanhamento da criança que está hospitalizada. Na qual, o professor que irá fazer o acompanhamento, objetivando não só a continuidade nos estudos, mas manter a rotina da criança, trazendo momentos prazerosos (SANTOS MMO, 2013). 
Certas histórias relatadas no grupo de entrevistados reafirmam e constatam que positivar a saúde que habita a doença, incentivando a imaginação e a criatividade do brincar da criança e do adolescente (sua vitalidade essencial) parece ser um recurso de efeitos objetivos e subjetivos importante. Esse recurso contribui para a manutenção da provisão ambiental no tratamento desses pacientes, assim como lhes assegura 0 sentimento de continuidade de existir (SANTOS ALM e PACHECO APA, 2010).

$E$, nos momentos em que os pacientes não conseguem responder ou chegar a uma resposta para o questionamento, Souza LPS, et al. (2012), afirma que no momento de debilidade, a compreensão da criança sobre que está se passando com ela fica dificultosa. Assim, não entende a doença e nem os tratamentos e, se retrai, prefere não buscar entendimento. Evidenciado pelas falas, que parecem retratar, certo sentimento de impotência, falar sobre o adoecer é complicado e se agrava quando esse adoecer se dá por uma doença crônica, e a esperança de futuro passa a ser incerta. Assim, frente à situação, a criança desenvolve comportamentos defensivos, sente raiva, muitos silenciam, outros preferem não pensar no futuro (SOUZA LPS, et al., 2012; TRINTENARO JC, et al., 2016).

\section{CONCLUSÃO}

A doença mal estabelecida na cognição infantil, aliada a uma comunicação inacessível dificulta a definição de maneiras adequadas de enfrentamento. Normalmente, a constatação da doença por parte das crianças advém de sintomas ou restrições físicas, sociais e alimentares existentes, provocando sentimentos confusos e emoções negativas. Nota-se que a interação com as crianças por meio dos "emojis" e a promoção da reflexão dos aspectos emocionais coadjuvantes do enfrentamento da doença, sinaliza que a ampliação das ferramentas profissionais para o manejo da dimensão psicoemocional faz-se necessária para uma eficiente qualificação do profissional de saúde. Assim, a boa relação médico-paciente-família é essencial durante todo processo; posto que, para que haja o enfrentamento adequado, é preciso que estejam cientes das condições da doença, tenham confiança e segurança nos profissionais de modo que objetive maior aceitação, esperança e positividade. Diante disso, faz-se imprescindível a adequação do ambiente hospitalar, a ampliação da compreensão da influência da intervenção psicoemocional, por meio da ludicidade nos diálogos, incluindo a percepção e acolhida da subjetividade do sujeito. Essas ferramentas ajudam na imaginação e na criatividade, influenciam a elaboração interna da criança diante da situação vivida. Todos esforços por parte da equipe de saúde são para que o paciente oncológico pediátrico se sinta entendido, cuidado e acolhido, com dignidade em seu tratamento, sendo esses elementos fundamentais para aumentar a efetividade e a humanização da proposta terapêutica.

\section{REFERÊNCIAS}

1. ALVES KMC, et al. The experience of parents of children with cancer in treatment failure conditions. Texto e ContextoEnfermagem, 2016; 25 (2).

2. BARDIN, L. Análise de conteúdo. Lisboa: São Paulo: Edições 70, 2011.

3. BRUM MV, AQUINO GB. Estudo do impacto do tratamento do câncer infantil nos aspectos emocionais dos cuidadores de crianças com diagnóstico da doença. Revista Científica Faminas, 2014; 10 (2): 98-117.

4. CAPRINIL FR, MOTTALL AB. Câncer infantil: uma análise do impacto diagnóstico. Psicologia: Teoria e Prática, 2017. 19(2): 164-176.

5. COSTA PF. O conceito de ambivalência em D.W.Winnicott. Dissertação (Mestrado em Psicologia) - Faculdade de Filosofia e Ciências Humanas. Universidade Federal de Minas Gerais, Belo Horizonte, 2016; 54-56 p.

6. COSTA TF, CEOLIM MF. A enfermagem nos cuidados paliativos à criança e adolescente com câncer: revisão integrativa da literatura. Revista Gaúcha de Enfermagem, 2010. 31(4): 776-784.

7. D'ALESSANDRO D. A linguística e a saúde na fronteira: uma abordagem multidisciplinar. Repositório Institucional UNILA, 2020.

8. FONSECA NC, et al. Influência do estresse sobre o sistema imunológico: example of construction and formatting of a scientific article. Faculdades Promove, 2014. 4-6 p.

9. GOLEMAN D. Inteligência Emocional: a teoria revolucionária que define o que é ser inteligente. $5^{\mathrm{a}}$ ed. Rio de Janeiro: Objetiva; 2011.

10. HILDEBRAND AK, et al. Coping with pediatric cancer: Strategies employed by children and their parentes to manage cancer-related stressors during treatment. Journal of Pediatric Oncology Nursing, 2011. 28(6): 344-354.

11. OTANI, MAP. Communication between health professional and patient: perceptions of women with breast cancer. Tese (Doutorado em Saúde Coletiva) - Faculdade de Ciências Médicas. Universidade Estadual de Campinas, Campinas, 2013; $221 \mathrm{p}$. 
12. PAIVA VLMO. A linguagem dos emojis. Trabalhos Linguísticos Aplicados, 2016 55(2): 379-99.

13. PIMENTEL LCMA, et al. Comunicação de notícias difíceis na formação médica: desenvolvendo competências relacionais. Revista de Educação da Universidade Federal do Vale do São Francisco, 2020. 10(21): 84-102.

14. SANTOS ALM, PACHECO APA. Há saúde na doença? In: Instituto Nacional de Câncer. Comunicação de notícias difíceis: compartilhando desafios na atenção à saúde. Rio de Janeiro: INCA; 2013; 115-123 p.

15. SANTOS MMO, et al. O trabalho pedagógico-educacional em classe hospitalar: um estudo de caso. Cairu em Revista, 2013; 2 (2): 158-173.

16. SEI MB, ZUANAZZI AC. A clínica psicanalítica com adolescentes: considerações sobre a psicoterapia individual e a psicoterapia familiar. Psicologia Clínica, 2016. 28(2): 89-108.

17. SILVA LF, CABRAL IE. As repercussões do câncer sobre o brincar da criança: implicações para o cuidado de enfermagem. Texto e Contexto- Enfermagem, 2014; 23 (4): 935-943.

18. SILVA PLN et al. Câncer infantil: vivências de crianças em tratamento oncológico. Revista Enfermagem em foco, 2016. 7(3/4): 51-55.

19. SOUZA LPS, et al. Câncer Infantil: Sentimentos manifestados por crianças em quimioterapia durante sessões de brinquedo terapêutico. Revista da Rede de Enfermagem do Nordeste, 2012; 13(3): 686-692.

20. TRINTENARO JC, et al. O paciente oncológico frente ao conhecimento da doença. Revista Psique, 2016; 1(2): $52-68$. 21. VALVERDE DLD, CARNEIRO MPSR. Suporte psicológico e a criança hospitalizada: o impacto da hospitalização na criança e em seus familiares. Psicologia.pt: O portal dos Psicólogos, 2011. 5 p.

22. VIEIRA CS et al. Rede e apoio social familiar no seguimento do recém-nascido pré-termo e baixo peso ao nascer. Revista Eletrônica de Enfermagem, 2010. 12(1):11-19. 